Fourth International Conference on Sustainable Construction Materials and Technologies http://www.claisse.info/Proceedings.htm

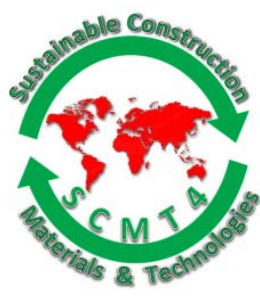

SCMT4

Las Vegas, USA, August 7-11, 2016

\title{
Characterization and Modeling of Hydration and Microstructure Formation for Blast Furnace Slag Cement
}

\author{
Toyoharu Nawa
}

Division of Sustainable Resources Engineering, Hokkaido University, JAPAN. E-mail: nawa@eng.hokudai.ac.jp

\begin{abstract}
Degree of hydration of cement minerals and BFS, amount of hydration products of pastes were determined by XRD/Rietveld method. The hydration mechanism of slag was also investigated, considering the role of calcium hydroxide as activator and the $\mathrm{Ca} / \mathrm{Si}$ ratio of $\mathrm{C}-\mathrm{S}-\mathrm{H}$. Assumed that for low $\mathrm{Ca} / \mathrm{Si}$ ratio, the $\mathrm{C}-\mathrm{S}-\mathrm{H}$ inner product resists strongly against ion diffusion and thus the hydration of BSF retards, an enhanced model for slag hydration was proposed. The validity of enhanced model is verified by both hydration degree and heat generation tests. The capillary porosity of BFS blended cement pastes is larger at lower hydration degree, and remarkably decreases as its hydration progresses. Gel water in BFS paste increase nonlinearly with the hydration degree of BSF. This implies that C-S-H produced from BFS hydration at later age has larger amount of gel water and becomes lower density, can fills in large pores more efficiently. Enhanced modeling of pore structure taking into account of these new findings could reproduce the experimental results of porosity and higher long-term strength development of BSF paste even though the hydration degree of BSF was lower than OPC.
\end{abstract}

\section{INTRODUCTION}

Realizing of sustainable society is a major driver for future innovations and prospects for development of construction industry. The main problem for the construction industry is that the global average $\mathrm{CO}_{2}$ emission per ton of cement manufactured, which is mainly due to the decarbonation of limestone, is estimated to be about 0.83 tons [Gielen and Tanaka 2007]. It is actually quite low compared to most other manufactured products. For example, compare it to steel, the global average $\mathrm{CO}_{2}$ emission per ton of steel manufactured rises up to about 3 tons of $\mathrm{CO}_{2}$, or for aluminum, it rises up to about 15 ton/ton of product [Gaetner 2011]. However, global cement production is estimated around 3.6 billion tons of cement were produced worldwide in 2011 [Gielen and Tanaka 2007], per year, and continues to increase due to megaurbanization and subsequent infrastructure development all over the world, predicted to rise to 5.8 billion tons by 2050 [Gartner 2009]. Thus, simply because of the enormous volumes of concrete produced globally every year, it is evident that any positive action that the cement manufacturing industry could take to reduce its specific $\mathrm{CO}_{2}$ emissions would contribute to reducing overall global Green House Gas 
emissions. If we are to tackle this perceived problem, energy efficient ways must be found to produce hydraulic binders that emit significantly less fossil $\mathrm{CO}_{2}$ during manufacture.

The most promising way to meet this rising demand is to continue increasing the use of supplementary cementitious materials (SCMs) such as fly ash, ground granulated blast furnace slag, silica fume and natural pozzolan. The practice of using SCMs is increasing, with the world average percent clinker in cement having decreased from $85 \%$ in 2003 to $77 \%$ in 2010, and it is projected to further decrease to $71 \%$ in the future [Gielen and Tanaka 2007]. While the replacement Portland cement clinker with SCMs is often driven by the pressure that comes from the global environmental issues to reduce $\mathrm{CO}_{2}$ emissions from concrete, the use of SCMs in concrete remains the relatively small amounts (5-20\% replacement of clinker) by economics and improvements in the long-term mechanical properties and durability of concrete, since the high volume clinker replacements result in losses in performance at early ages, and larger drying and autogenous shrinkage that tends to induce cracking and decrease durability. The use of SCMs in concrete. On the other hand, many past studies shows that concrete made with slag blended cement has many advantages, including better chloride resistance, lower permeability and higher strength at later age. From the viewpoint of circular economy and sustainable development, blast furnace slag is a promising mineral admixture in the concrete industry.

A key issue in materials design based on materials science is to establish quantitative relationships between processing, structure, and properties. It is broadly agree that for ordinary Portland cement, higher strength usually derives from a higher degree of hydration. However, when we switch to blast furnace blended cement (BSF) from Portland cement (PC), it seems insufficient to attribute strength development only to the hydration process. For instance, it is well known that under room temperature when PC is replaced partially by BFS, strength decreases at an early age while higher strength can be achieved at a later age. On the other hand, researchers [Luke 1987, Lumley 1996, Demoullian1980, Battagin 1992, Sakai 2004] indicate that the hydration degree of slag ranges from $30 \%$ to $70 \%$ after long time curing such as 1-2 years, which is lower than that of PC. Obviously BFS gains higher strength than PC at a later age, even if the hydration degree is lower than that of PC. Microscopic observation [Regourd 1987, Escalant-Garcia 2001, Tan 1998] by Scanning Electron Microscopy (SEM) indicates that the BFS matrix with full curing has a denser structure than PC, and porosity analysis such as Mercury Intrusion Porosimetry (MIP) [Feldman 1981, Feng 1989, Aldea 2000, Kwak 2004] also shows that at a later age the pore distribution curve moves towards a much finer diameter. Therefore, dense pore-structure can be considered to contribute more than hydration for the strength of BFS at later ages. Actually, other properties of BFS that differ from PC may be also related to the pore-structure. The moisture loss of BFS under drying conditions is reported to be less than that of PC [Dan 2009, Hogan 1981], which can be explained by finer pores and stronger retention of water. It is also reported that drying shrinkage of BFS is larger than PC, especially for those cases with sufficient curing [Brooks 1992, Li 20011, Chern 1989]. This larger shrinkage deformation can be attributed to the finer pore structure, because higher capillary tension force may be induced in the paste. Beside, BFS concrete is more sensitive to the curing conditions. Insufficient water supply during curing may retard the hydration process and cause a significant decrease in the long-time properties. Therefore, for the purpose of promoting the efficient application of BSF, it is of great necessity proper modeling and simulation of its hydration and subsequent microstructure 
formation are necessary in order to evaluate or predict the macro-properties of BFS concrete based on micro-information.

This paper summarizes the advances in our studies (Sagawa 2006a, 2006b, 2010, Ishida 2011, Luan 2012) on characterization and modeling of hydration and pore structure formation achieved in the last decade to improve the material design for BSF concrete. The hydration of BSF and pore structure of the BFS matrix can be properly simulated. Furthermore, based on the correct information on pore-structure, prediction of the macro properties of BFS concrete such as thermal temperature rise and strength development could also be improved.

\section{CHARACTERAZATION FOR HYDRATION AND MICROSTRUCTURE FOR BSF}

The accurate measurement of the degree of reaction of SCMs in hydrating blended cements is necessary to unravel the parameters governing SCM hydration. Several different methods has been proposed and applied, but all previously proposed methods have more or less serious limitations. The selective dissolution approaches are unreliable as they show large, unrealistic discrepancies with other methods and problems with inter-laboratory reproducibility [Ohsawa 1985, Luke 1987, Ben Haha 2010, Kocaba 2012]. Application of image analysis to electron microscopy images and element maps has shown promising results for SCMs [Kocaba 2012, Weerdt 2011, Deschner 2013]. However, the proposed approaches are time-demanding and cannot resolve the reaction of particles smaller than about $2 \mu \mathrm{m}$, rendering the method unsuitable for fine materials such as silica fume and metakaolin. A more generally applicable method makes use of ${ }^{29} \mathrm{Si}$ and ${ }^{27} \mathrm{Al}$ solid-state NMR spectroscopy. The method has been successfully applied to SCMs [Saout 2011,Hjorth 1988, Lothenbach 2012]. However, widespread use will remain limited because access to solid-state NMR equipment is restricted. ${ }^{29} \mathrm{Si}$ NMR data acquisition is timeconsuming (1-2 days per measurement) and measurements are restricted to systems with low levels of paramagnetic ions. XRD is the most prominent analytical techniques in the characterization of Portland cement based materials because of ease and speed of measurement and its accuracy. Full XRD profile fitting methods such as the Rietveld method can realize the more quantitative analysis of crystalline phases in unhydrated and hydrated cement has resolved crystal structures and can be quantified. It is wellknown that the glass content of slag can be determined by thermal analysis: the first reversible exothermic peak in the temperature range $700-800{ }^{\circ} \mathrm{C}$ corresponds to the glass-transition temperature, the next two exothermic peaks with well-defined maxima in the range $925-1040{ }^{\circ} \mathrm{C}$ are attributed to the devitrification process. Using X-ray diffraction, these peaks were respectively assigned to merwinite (metastable phase) and melilite (solid solution gehlenite to akermanite) [Regourd 1980, Fredericci 2005]. It has been suggested that quantification of unhydrated BFS in hardened BFS blended cement can be determined by Rietveld method to measure the crystallized BFS.

Fig. 1 shows the degree of hydration of $\mathrm{BFS}$ and $\mathrm{C}_{3} \mathrm{~S}$ in cement. Hydration degree of finer BFS with around Blaine fineness of $6000 \mathrm{~cm}^{2} / \mathrm{g}$ (representing B6 in Fig.1, N, M and L is ordinary, moderate heat and low heat Portland cement) was higher than coarse BFS with fineness of $4000 \mathrm{~cm}^{2} / \mathrm{g}$. Hence it can be seen that reactivity of BFS is higher as the particle size of BFS is small. In addition, hydration reactivity of BFS was strongly affected by the amount of $\mathrm{C}_{3} \mathrm{~S}$ in base Portland cement, hydration of BFS tended to 
be delayed at smaller amount of $\mathrm{C}_{3} \mathrm{~S}$ in base Portland cement. On the other hand, it is confirmed that the hydration of $\mathrm{C}_{3} \mathrm{~S}$ in blended cement accelerated by the presence of BSF. This implies that BFS plays the role of precipitation site of C-S-H which is the hydrate of $\mathrm{C}_{3} \mathrm{~S}$.
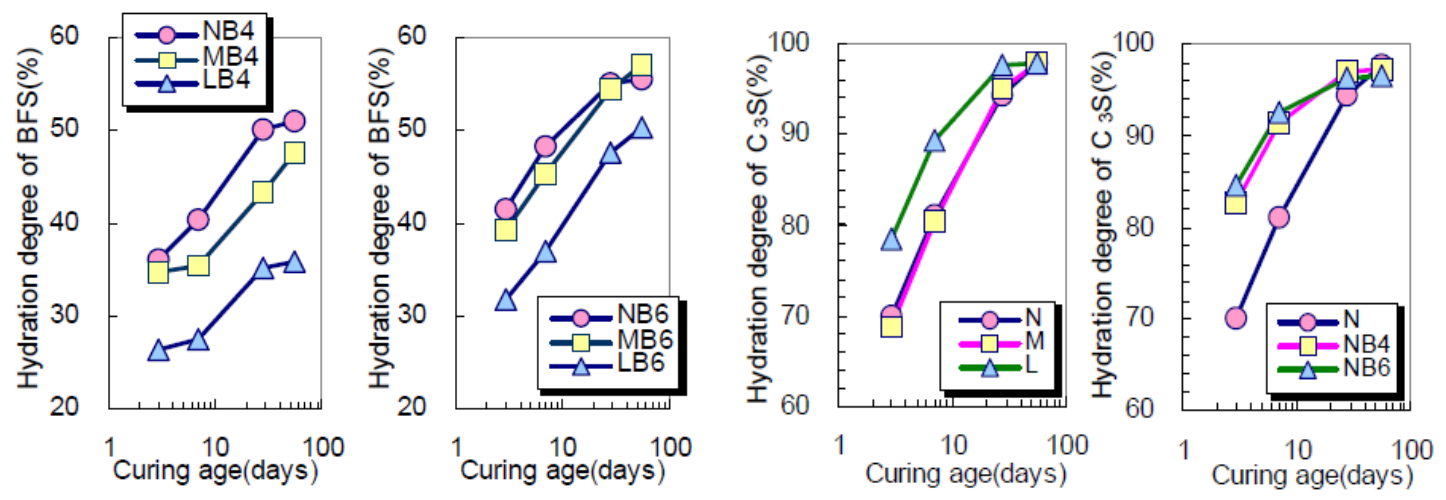

Fig.1 Degree of hydration of BFS and $\mathrm{C}_{3} \mathrm{~S}$ in BSF blended cement.

It is well agreed that the principle hydrates of slag are C-S-H gels. Compared with Portland cement, researchers found that as the slag ratio increases, C-S-H gels produced by slag show a lower $\mathrm{Ca} / \mathrm{Si}$ ratio (Harrisson et al. 1987; Shi et al. 1992; Richardson and Groves 1992; Gollop and Taylor 1992, 1996), as illustrated in Fig. 2. The physical properties of C-S-H may vary due to the reduced Ca/Si ratio.
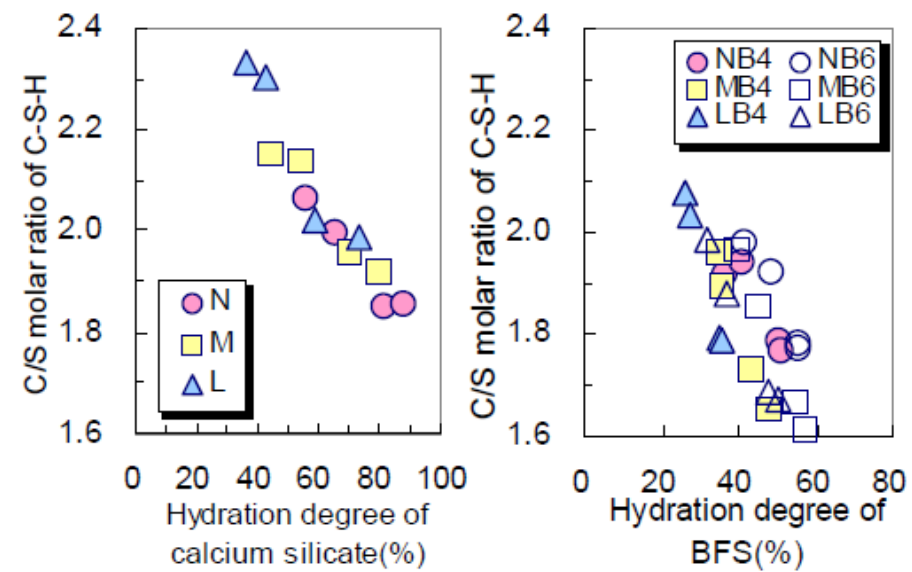

Fig.2 Ca/Si ratio of C-S-H in hydrated Portland and BSF blended cements

Physical water was categorized into capillary water and water insidegel grains, i.e. gel and interlayer water. In experiments, it is impossibleto divide capillary, gel and interlayer water precisely. Hence the author and coworkers define the capillary, gel and interlayer water: the weight loss by dring at $40{ }^{\circ} \mathrm{C}$ for specimens with saturated condition was considered as the total capillary water. The remaining physical water was regarded as the sum of the gel and interlayer water. Then the specimens were exposed at 
$105^{\circ} \mathrm{C}$ to remove all the gel and interlayer water. The weight loss from $40{ }^{\circ} \mathrm{C}$ to $105^{\circ} \mathrm{C}$ was measured as gel and interlayer water.

ig. 3 shows experimentally calculated capillary pore, and gel and interlayers pores volume, as a function of hydration degree of BSF. One can find the experimantal data agree with theoretical value predicted by the Powers' model [Powes 1960]: the upper line and bottom line show the total pore volume and capillary pore volume, respectively. Finally, the specimens were heated up to $1000{ }^{\circ} \mathrm{C}$ to remove chemically combined water. The weight percentage is defined as the lost water to remaining paste weight after heating at $1000{ }^{\circ} \mathrm{C}$. The definition of the gel and interlayer water needs to be clarified. As the definition in the test, the specimens were dried at $40{ }^{\circ} \mathrm{C}$ to remove capillary pore water and then exposed at $105{ }^{\circ} \mathrm{C}$ to measure the gel and interlayer water loss. Actually, after drying at $40{ }^{\circ} \mathrm{C}$, a little water still remained in capillary pores while some of the gel water evaporated. Therefore, strictly speaking, the gel and interlayer water measured do not coincide completely. However, since only a small part of the gel water was lost during drying at $40{ }^{\circ} \mathrm{C}$, it can be reasonably assumed that the test result is approximately comparable with the computed value.

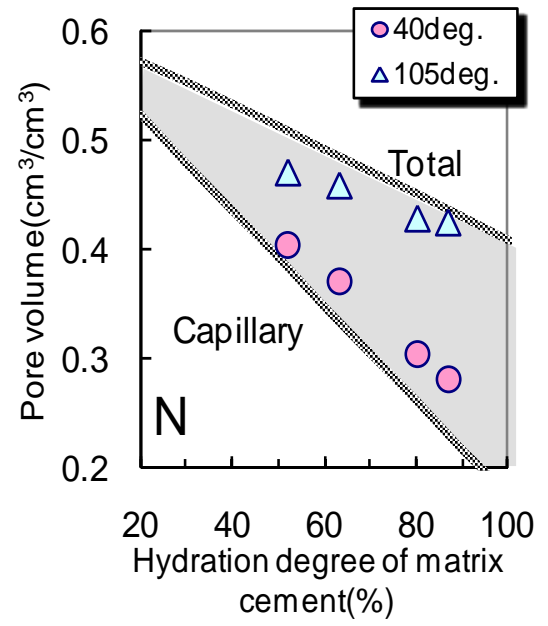

Fig.3 Relation between hydration degree of cement and pore volume.

Fig. 4 illustrates the relationship between the $\mathrm{Ca} / \mathrm{Si}$ ratio and the $\mathrm{H} / \mathrm{Si}$ ratio of $\mathrm{C}-\mathrm{S}-\mathrm{H}$, the relationship between the ratio of $\mathrm{Ca} / \mathrm{Si}$ ratio and gel water in $\mathrm{C}-\mathrm{S}-\mathrm{H}$, respectively. The chemical combined water decreased with the decrease of the $\mathrm{Ca} / \mathrm{Si}$ ratio of $\mathrm{C}-\mathrm{S}-\mathrm{H}$, In contract, the gel and interlayer water in BSF paste showed a reverse tendency. It increased with the decrease of the $\mathrm{Ca} / \mathrm{Si}$ ratio of $\mathrm{C}-\mathrm{S}-\mathrm{H}$, while for PC paste it was constant deposite the $\mathrm{Ca} / \mathrm{Si}$ ratio of $\mathrm{C}-\mathrm{S}-\mathrm{H}$. Therefore, when one consider a sum of chemical combined water and gel and interlayer water as watedr content, the $\mathrm{H} / \mathrm{Si}$ ratio is gradually decreased with the decrease of the $\mathrm{Ca} / \mathrm{Si}$ ratio of $\mathrm{C}-\mathrm{S}-\mathrm{H}$ for PC paste, while for BFS paste the H/Si ratio increased from around 3 to around 6 as the $\mathrm{Ca} / \mathrm{Si}$ ratio decresing. Here, we focus only on the gel and interlayer water, calculated as the mass percentage of gel water in $\mathrm{C}-\mathrm{S}-\mathrm{H}$, which were arranged in relation to the $\mathrm{Ca} / \mathrm{Si}$ ratio is the right view of Fig. 4. For the PC paste, the sum of gel and interlayer water was substantially constant around $15 \%$ regardless of the $\mathrm{Ca} / \mathrm{Si}$ ratio, whereas that in BFS paste significantly increased as 
decreasing the $\mathrm{Ca} / \mathrm{Si}$ ratio. Since $\mathrm{Ca} / \mathrm{Si}$ ration of $\mathrm{C}-\mathrm{S}-\mathrm{H}$ decreased with age, these resuls implies that the gel and interlayer water in C-S-H for BSF paste increase with the age.

Form the above-mentioned results, one can understand that the fraction of gel and interlayer water in C-S$\mathrm{H}$ in PC paste is constant, while for BFS paste it was varied as hydration progressed. This can explain the fact that the capillary pore volume of BFS paste is larger than PC paste in an earler age, but it decrease significantly as BSF hydrattin progresses, and at later age it became smaller than PC paste.
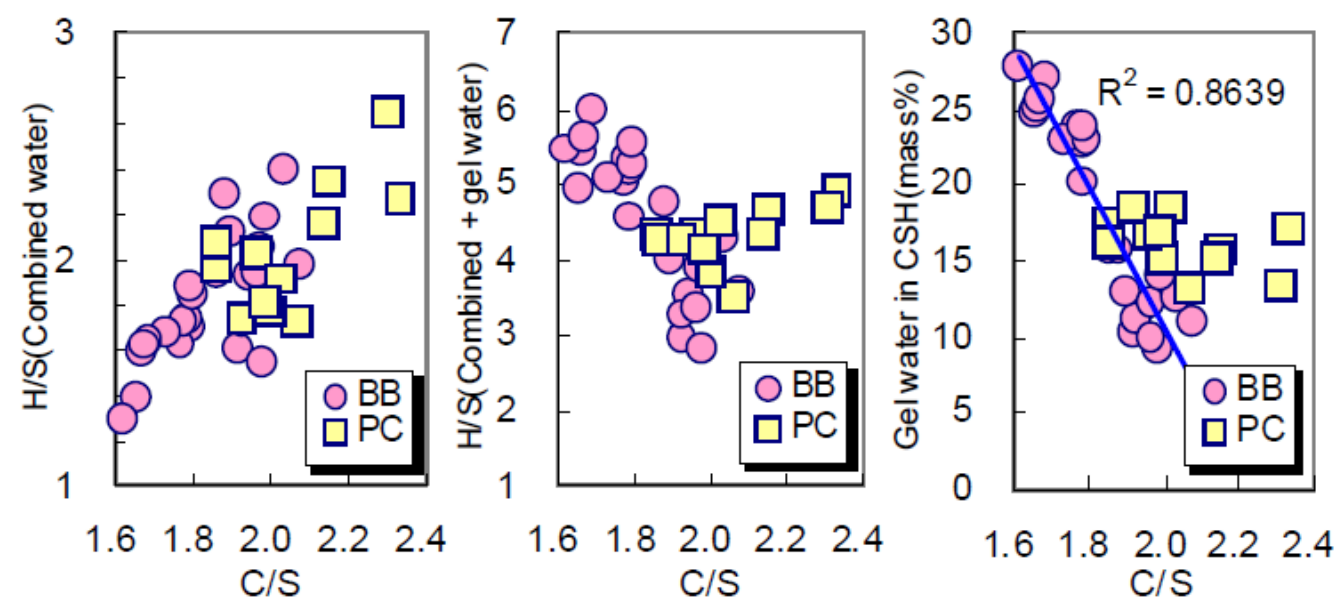

Fig.4 Chemical combined $\mathrm{H}_{2} \mathrm{O}$ to Si ratio (left), Chemical and gel and interlayer $\mathrm{H}_{2} \mathrm{O}$ to Si ratio (middle) and gel and interlayer water content in C-S-H represented as a function of $\mathrm{Ca} / \mathrm{Si}$ ratio of C-S-H.

\section{ENHANCED PORE STRUCTURE MODEL FOR BSF AND ITS VERIFICATION}

Otabe et al. (2005) is the strength development model which follows the concept proposed by Schiller (1958), in which it is assumed that the strength of concrete or mortar is principally related to capillary porosity development, because capillary pores are much larger than gel and interlayer pores and influence strength more significantly. As shown in Fig. 5, the model can predict the strength development of Portland cement (noted N in figure) accurately, while BSF (NB) had lower strength at an early age but reached higher strength at $91 \mathrm{~d}$ as hydration went on. This suggests that for BSF, more capillary pores should be filled by hydrates at later age. 


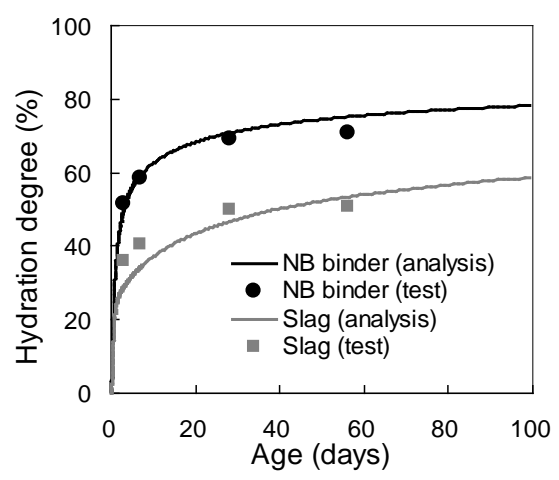

Fig.5 Comparison of strength development between the predict value due to original model and the experimental data.

From above discussion one can expect that when the degree of hydration is the same, the density of C-S$\mathrm{H}$ produced due to BSF hydration may be smaller than that due to PC hydration. Fig. 6 shows a sum of the gel and interlayer water ratio as a function of the chemically combined water. The increase of chemically combined water reflects the hydration processes. For PC paste (noted N in figure), good agreement is obtained, but for BFS paste (NB), the analysis apparently underestimates gel and interlayer water development at a later age. Unlike the linear increase in N, all the BFS test data show a tendency toward nonlinear increase, with higher gel and interlayer water content gain at a later age. However, the analysis gives a linear increase for NB. Therefore it is rational to deduce that the current model is only applicable to PC rather than BFS due to inconsistent gel and interlayer pore water assessment. This inconsistency leads to underestimation of gel and interlayer porosity, and therefore overestimation of capillary porosity for BFS, which is also the cause of discrepancy of strength in Fig. 5. Hence, Ishida et al (20??) modified the pore-structure prediction model considering the impact of slag hydration on the gel and interlayer water. The results due to enhanced model are illustrated in Fig. 7. It is obvious that the enhanced model shows nonlinear increase and higher gel and interlayer water at a later age, which is consistent with the test results. Therefore, from the viewpoint of micro-physical properties of the matrix, the enhancement on the intrinsic porosity provides better simulation for BFS.

It is reported that C-S-H of BFS has a lower Ca/Si ratio [Talling 1989, Richardson 1992, Regourd 1983, Harrisson 1986], which may contribute to gel grains and induce higher grain strength. Therefore, another modification for the ultimate strength of C-S-H is requested in order to estimate BSF matrix. The ultimate strength of $\mathrm{C}_{3} \mathrm{~S}$ and $\mathrm{C}_{2} \mathrm{~S}$, slag are assumed to be $215 \mathrm{MPa}, 250 \mathrm{MPa}$, and $260 \mathrm{MPa}$. As shown in Fig. 9, enhanced model agrees with the experimental data well: at the early age, the strength of BFS (NB) was less than PC (N), BFS tended to gain higher strength at later age as hydration progressed. 

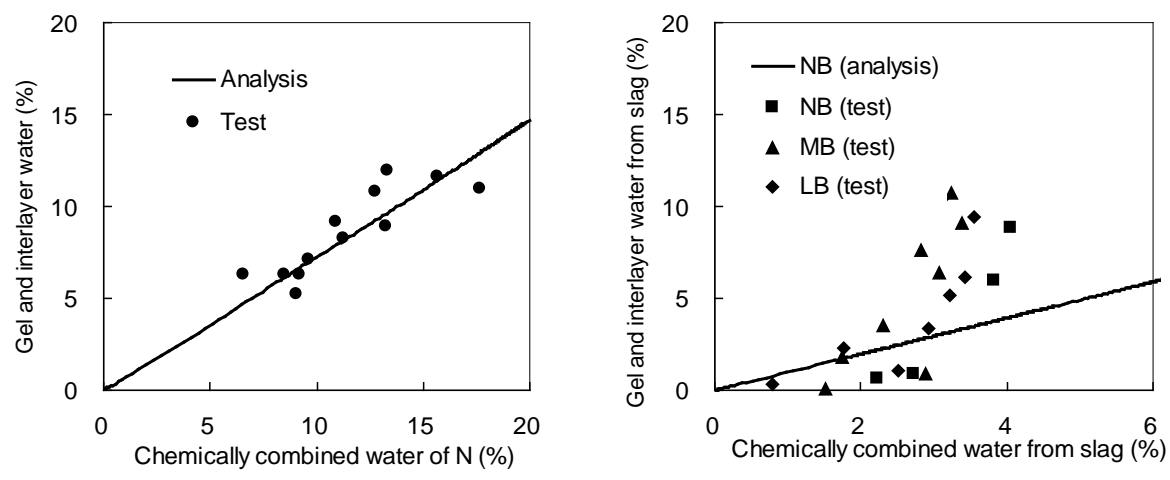

Fig. 6 Comparison of chemically combined water in hydrated pastes made with ordinary Portland cement (N) and BSF blended cements (NB, MB, LB).

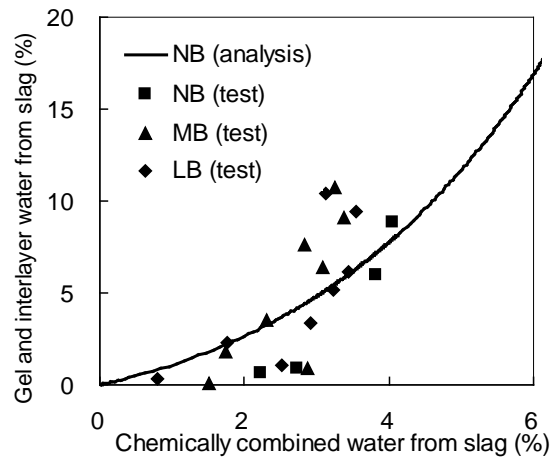

Fig.7 Gel and interlayer water in BSF blended cement paste (NB) based on enhanced model

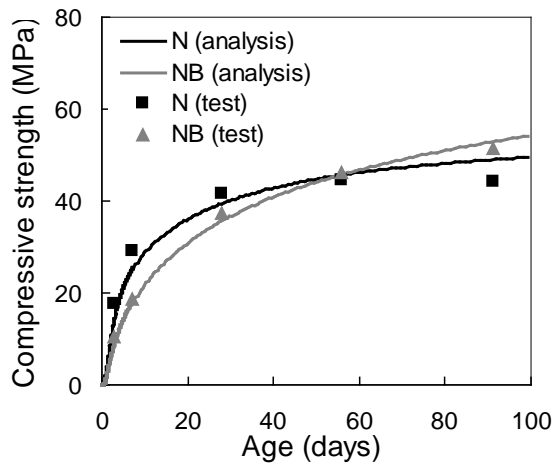

Fig.8 Comparison of strength development based on enhanced model

\section{ENHANCED ING HYDRATION MODEL FOR BSF AND ITS VERFICATION}

Kishi $(1994,1997)$ and Maekawa et al. (2008) developed a multi-component hydration heat model based on the Arrhenius law of chemical reaction, in which parameters are temperature, available free water, $\mathrm{CH}$ content and slag fineness, the hydration heat rate under real condition is given by following the equation:

$$
H_{s g}=\min \left(\beta_{s g}, \lambda_{s g}\right) \cdot H_{s g, T_{0}}\left(Q_{s g}\right) \exp \left\{-\frac{E_{s g}}{R}\left(\frac{1}{T}-\frac{1}{T_{0}}\right)\right\}
$$

where $H_{\text {sg }}$ is the hydration heat rate under real condition, $H_{s g, T 0}$ is the reference heat rate at $293 \mathrm{~K}, Q_{s g}$ is the accumulated heat during hydration, $E_{s g}$ is the activation energy of slag, $R$ is the gas constant, $T_{0}$ is the reference temperature (293 K), and $T$ is the real temperature. $\beta_{\mathrm{sg}}$ is the coefficient considering the effect of available free water, and $\lambda_{\mathrm{sg}}$ is the coefficient expressing hydration activation due to $\mathrm{CH}$ insufficiency. This model has been verified by adiabatic temperature rise tests for both Portland cement and slag blended cement concrete. On the other hand, verification of the hydration degree of slag has not been carried out, because of the scarcity of reliable data when the model was established. Fig. 6 shows the 
comparison between experimental and analysis values of the hydration degree of BSF. It is obvious that extreme large differences between them exist.
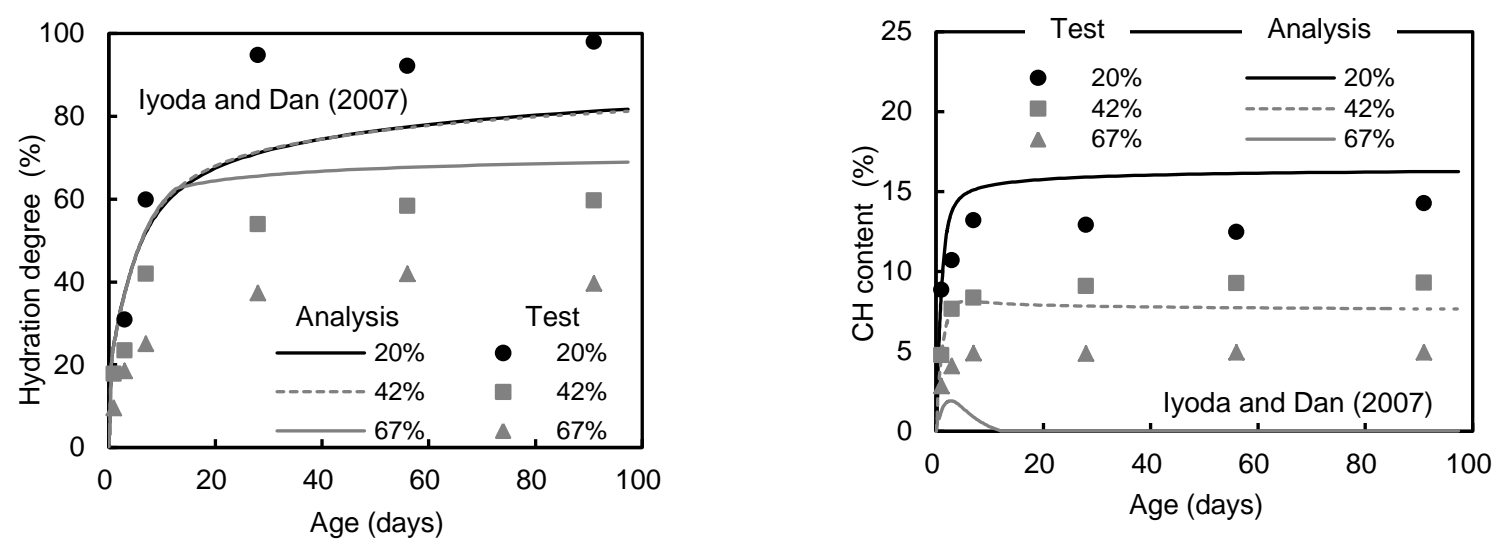

Fig. 9 Comparison of experimantal data with value of original model analysis for hydration degree (left side ) and $\mathrm{CH}$ content (right side)

Herein the hydration scheme of slag is discussed according to the basic information of activation (Tanaka et al. 1983; Taylor 1990). At the starting stage, due to the activation by $\mathrm{Ca}^{2+}$, the protective film on the surface of the slag particle is destroyed. The internal structure, which is an anionic network composed of $\mathrm{O}$, Si and other elements, starts to decompose, and silicate ions such as $\mathrm{Si}(\mathrm{OH})_{4}$ are released into the solution. When silicate ions contact $\mathrm{Ca}^{2+}$, a reaction occurs and hydrates start to precipitate. Like in the case of Portland cement, hydrates from slag can be divided into two categories, i.e. the inner product and the outer product. The inner product consists of hydrates generated inside the radius of the original particle and closely bond around an unhydrated core, while the outer product precipitates outside the range of the original particle and fills in capillary pores. In order to sustain hydration, it is necessary for silicate ions released from slag to diffuse outside the inner product, or alkali cations to diffuse inside. The inner product may show resistance against ion diffusion, i.e. as hydration goes on and the thickness of the inner product increases, the diffusivity of ions through the inner product becomes lower. Accordingly, the reaction comes slower or even stagnates. Therefore, the thickness of the inner product is a crucial factor that dominates the hydration rate of slag.

Furthermore, when we discuss the resistance effect of the inner product, not only its thickness but also the various other physical properties have to be taken into account. As discussed above, increasing the slag ratio varies the $\mathrm{Ca} / \mathrm{Si}$ ratio of $\mathrm{C}-\mathrm{S}-\mathrm{H}$, and accordingly one should consider the impact of physical properties of C-S-H on the hydration process from two aspects: First, since C-S-H with a lower $\mathrm{Ca} / \mathrm{Si}$ ratio has a morphology that is foil-like rather than fibrillar, the tortuosity of gel pores becomes higher. This implies more twists and forks in pores, resulting in a much longer path for ions to diffuse through the inner product. The other factor may be the alternated electric charge on the surface of C-S-H. As indicated by Elakneswaran et al. (2009), pores with a diameter of less than $10 \mathrm{~nm}$ show the electrical double layer (EDL) effect. The inner product contains mainly gel pores and a large proportion of gel pores have a diameter smaller than $10 \mathrm{~nm}$, and thus the EDL effect of the inner product is obvious. In the case of C-S- 
$\mathrm{H}$ with a high $\mathrm{Ca} / \mathrm{Si}$ ratio, the surface is positively charged. The repelling effect of the positive charge layer restrains the movement of $\mathrm{Ca}^{2+}$ towards the inner product. The principal ion movement is that of silicate ions that are released through the inner product. When the electric charges become less positive or even negative due to the lower $\mathrm{Ca} / \mathrm{Si}$ ratio, the principal ion movement may change. Due to the absorbing effect, more $\mathrm{Ca}^{2+}$ ions move toward the inner product and react with silicate ions near it. The reverse ion movement implies that denser inner product having stronger resistance against ion diffusion is formed. Further ion diffusion may be blocked and the hydration rate afterwards is reduced significantly. The above discussion about the relationship between the hydration of the slag and inner product is illustrated in Fig. 5. Accordingly, the authors conclude that for a lower $\mathrm{Ca} / \mathrm{Si}$ ratio due to both higher tortuosity and reversed electric charge, the inner product layer shows higher resistance to ion movement. This may be the main reason that the hydration degree decreases as the slag ratio increases.
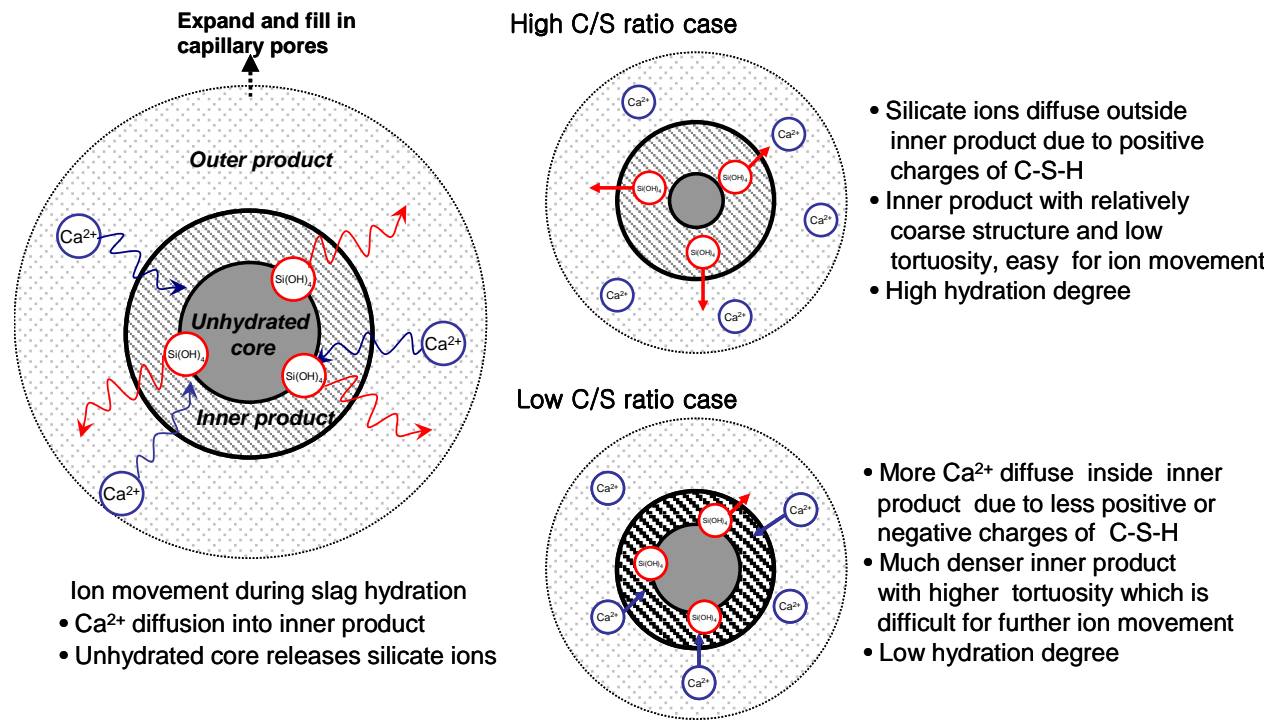

Fig. 10 Influence of inner product on ion movement and hydration of slag

From above discussion, it can be seen that the hydration process is closely associated with the inner C-S$\mathrm{H}$ product because of its resistance to ion movement. This resistance depends on both the thickness and intrinsic properties of C-S-H. In the original model proposed by Kishi and Maekawa et al., although the thickness of the inner product is considered, the various intrinsic properties of C-S-H determined by the $\mathrm{Ca} / \mathrm{Si}$ ratio are not taken into account. On the other hand, inefficiency coefficient of $\mathrm{CH}, \lambda_{\mathrm{sg}}$, seems to be able to ignore since sufficient amount of $\mathrm{CH}$ exists in the paste even for high slag ratios. After all, all factors are integrated into coefficient $\beta_{\mathrm{sg}}$. Since the hydration degree is related to the fraction of free water $\omega_{\text {free}}$, slag fineness $S_{\mathrm{sg}}$, and the effect of the inner product. The $\mathrm{Ca} / \mathrm{Si}$ ratio of C-S-H shows a clear correlation with the slag ratio, and thus the slag ratio seems a proper index of the effect of the inner product. Further as the inner product becomes thicker, the ion diffusion is strongly resisted so the hydration rate decreases sharply rather than gradually. This fact request the exponential formula seems appropriate to describe the significant relationship between inner product thickness and the resistance effect. Therefore, the effect of the inner product is proposed by a new coefficient $\chi$, defined as follows: 


$$
\chi=\exp \left(-a \cdot \eta_{s g}^{b}\right)
$$

where $\eta_{\mathrm{sg}}$ is the thickness of the inner product. $a$ and $b$ are intrinsic parameters that are the functions of the slag ratio. In fact, the value of parameter $\chi$ depends on the intrinsic properties of C-S-H which depends on the $\mathrm{Ca} / \mathrm{Si}$ ratio and its influence on ion movement. The value of parameter $\chi$ decreases as the thickness of the inner product $\eta_{\mathrm{sg}}$ increases, which implicitly represents the resistance by the inner product to ion diffusion. Besides, for a higher slag ratio, the parameter $\chi$ decreases more sharply from the beginning. This has clear physical meaning that the $\mathrm{C}-\mathrm{S}-\mathrm{H}$ inner product has a stronger retardation effect on ion movement the lower the $\mathrm{Ca} / \mathrm{Si}$ ratio. Integrating $\chi$ into $\beta_{\mathrm{sg}}$, it is applicable to the simulation of the development of the hydration degree for various slag ratios. Accordingly, in the enhanced model, the new expression for $\beta_{\mathrm{sg}}$ is given by:

$\beta_{s g}=\left\{1-\exp \left\{-r\left\{\left(\frac{\omega_{\text {free }}}{20.0}\right) / s_{s g}^{\frac{1}{2}}\right\}^{s}\right\}\right\} \cdot \chi$

where $r$ and $s$ are the material constants.

The enhanced model is verified by experiments. As shown in Fig.11, the analytical results are much improved.

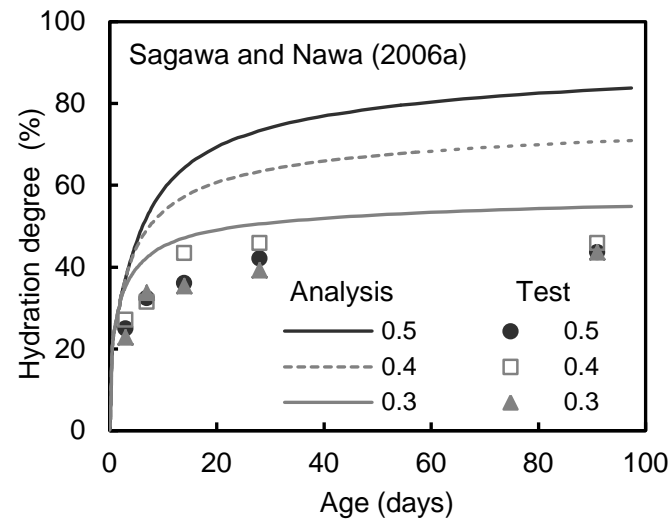

(a) Original model

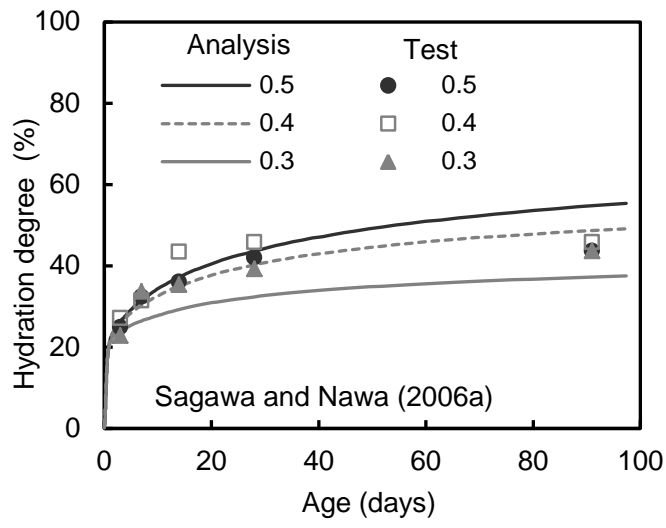

(b) Enhanced model

Fig. 11 Comparison of hydration degree based on enhanced model with original model: the water/binder ratios are $0.3,0.4$ and 0.5 , slag replacement ratio is $50 \%$, and slag powder with JIS fineness grade of 4000 is used. 


\section{CONCLUSIONS}

The following general conclusions can be drawn from the study provided in the paper:

- Rietveld analysis for unhydrated and hydrated BFS sample crystallized BFS with heat treatment is available to determine the hydration degree of compounds in BSF.

- Enhanced pore structure model was proposed for the BFS matrix. As the degree of hydration increases, more gel and interlayer pores are gained and hydration product fills in the capillary pores more efficiently, resulting in higher strength in a later age. Verification by strength experiment showed good agreement.

- The hydration process of BSF in cement is investigated focusing on the intrinsic properties of the inner product. Since the $\mathrm{Ca} / \mathrm{Si}$ ratio of $\mathrm{C}-\mathrm{S}-\mathrm{H}$ decreases as the slag ratio increases, resulting in both higher tortuosity and changed positive electric charge accumulation in C-S-H, it is assumed that the C-S-H inner product has a strong resistance to ions movement, and therefore the subsequent hydration tends to be retarded. Based on the above assumption, an enhanced model is proposed, taking into account the resistance effect. Finally, the enhanced model is applied to simulation of slag hydration, and the results indicate good agreement with the experiment data.

\section{ACKNOWLEDGEMENTS}

I gratefully acknowledge Prof. T. Ishida from University of Tokyo, Associate Prof. T. Sagawa from Maebashi Institute of Technology, and Associate Prof. Y. Luan from Saitama University.

\section{REFERENCES}

Aldea, C.M., Young, F. and Wang, K. (2000). "Effects of curing conditions on properties of concrete using slag replacement”, Cement and Concrete Research, 30 (3), 465-472.

Battagin, A.F. (1992). "Influence of degree of hydration of slag on slag cement”, Proceedings of the 9th International Congress on the Chemistry of Cement, 3, 166-172.

Ben Haha, M., De Weerdt, K., Lothenbach, B. (2010). "Quantification of the degree of reaction of fly ash”, Cement and Concrete Research, 40, 1620-1629.

Brooks, J.J., Wainwright, P.J. and Boukendakji, M. (1992). "Influence of slag type and replacement level on strength, elasticity, shrinkage and creep of concrete”, ACI Special Publication, 132, 1325-1341.

Brunet, F., Charpentier, T., Chao, C.N., Peycelon, H. and Nonat, A. (2010). "Characterization by solidstate NMR and selective dissolution techniques of anhydrous and hydrated CEM V cement pastes", Cement and Concrete Research, 40, 208-219.

Chern, J.C. and Chan, Y.W. (1989). "Deformations of concretes made with blast-furnace slag cement and ordinary portland cement”, ACI Materials Journal, 86 (4), 372-382.

Dan, Y., Iyoda, T., Ohtsuka, Y. and Sagawa, Y. (2009). "The relationship between curing condition and durability on concrete using blast-furnace slag cement”, Division E, Journals of JSCE, 65 (4), 431441 (In Japanese).

Demoulian, E., Gourdin, P., Hawthorn, F., and Vernet, C. (1980) "Influence of slags chemical composition and texture on their hydraulicity", Proceedings of 7th International Congress on the Chemistry of Cement, 2, pp. 89-104.

Deschner, F., Munch, B. and Winnefeld, F. (2013). "Quantification of flyash in hydrated, blended Portland cement pastes by backscattered electron imaging”, Journal of Microscopy, 251, 188-204 
Elakneswaran, Y., Nawa, T. and Kurumisawa, K., (2009). "Electrokinetic potential of hydrated cement in relation to adsorption of chlorides." Cement and Concrete Research, 39(4), 340-344.

Escalante, J.I., Gomez, L.Y., Johal, K. K., Mancha. Mendoza, G. and Mendez, J. (2001). "Rectivity of blast-furnace slag in Portland cement blends hydrated under different conditions", Cement and Concrete Research, 31, 1403-1409.

Feldman, R.F. (1981). "Pore structure formation during hydration of fly ash and slag cement blends, effects of fly ash incorporation in cement and concrete", Proceedings of Materials Research Society, 124-133.

Feng, Q.L., Lachowski, E.E., and Glasser, F.P. (1989), "Densification and migration of ions in blast furnace slag-portland cement pastes”, Materials Research Society Symposium Proceedings, 136, 263272.

Fredericci, C., Zanotto, E.D. and Ziemath, E.C. (2000). "Crystallization mechanism and properties of a blast furnace slag glass”, J. Non-Cryst. Solids, 273 (1-3), 64-75.

Gartner, E.M. (2009) "Cohesion and expansion in polycrystalline solids formed by hydration reactions The case of gypsum plasters", Cement and Concrete Research, 39 289-295.

Gartner, E.M. (2011). “A physico-chemical basis for novel cementitious binders”, Cement and Concrete Research, 41, 736-749

Gielen, D. Tanaka, K. (2007). "Energy efficiency and $\mathrm{CO}_{2}$ emission reduction potentials and policies in the cement industry: towards a plan of action”, Proceedings of the IEA/WBCSD Workshop on Energy Efficiency and $\mathrm{CO}_{2}$ Emission Reduction Potentials and Policies in the Cement Industry, Paris, September International Energy Agency, Paris, 4-5.

Gollop, R. S. and Taylor, H. F. W., (1992). "Microstructural and microanalytical studies of sulfate attack: I. ordinary Portland cement paste." Cement and Concrete Research, 22(6), 1027-1038.

Gollop, R. S. and Taylor, H. F. W., (1996). "Microstructural and microanalytical studies of sulfate attack: IV. reactions of a slag cement paste with sodium and magnesium sulfate solutions." Cement and Concrete Research, 26(7), 1013-1028.

Harrisson, A.M., Winter, N.B. and Taylor, H.F.W. (1986). "Microstructure and microchemistry of slag cement pastes”, Materials Research Society Symposium Proceedings, 85, 213-222.

Hjorth, J., Skibsted, J. and Jakobsen, H.J. (1988). “29 Si MAS NMR studies of Portland cement components and effects of microsilica on the hydration reaction, Cement and Concrete Research. 18, 789-798.

Hogan, F.J. and Meusel, J.W. (1981). "Evaluation for durability and strength development of a ground granulated blast furnace slag”, Cement, Concrete and Aggregates, 3 (1), 40-52.

Ishida, T., Luan, Y., Sagawa, T. and Nawa, T. (2011). "Modeling of early age behavior of blast furnace slag concrete based on micro-physical properties", Cement and Concrete Research, 41, 1357-1367

Kishi, T. and Maekawa, K. (1996). "Multi-component model for hydration heat of blended cement with blast slag and fly ash, Journal of Materials.” Concrete Structures and Pavements (JSCE), 33, 131-143. (In Japanese)]

Kishi, T. and Maekawa, K. (1997). "Multi-component model for hydration heating of blended cement with blast furnace slag and fly ash.” Concrete library of JSCE, 30, 125-139.

Kocaba, V., Gallucci, E. and Scrivener, K.L. (2012). Methods for determination of degree of reaction of slag in blended cement pastes, Cement and Concrete Research, 42 (2012) 511-525.

Kwak, D. (2004). "A fundamental study on pore structure affecting carbonation of concrete", Ph.D. thesis, Tokyo Metropolitan University (In Japanese).

Le Saoût, G., Ben Haha, M., Winnefeld, F. and Lothenbach, B. (2011). "Hydration degree of alkaliactivated slags: a ${ }^{29} \mathrm{Si}$ NMR study”, J. Am. Ceram. Soc., 94 , 4541-4547.

Lee, K.M., Lee, H.K., Lee, S.H. and Kim, G.Y. (2006). Autogenous shrinkage of concrete containing granulated blast-furnace slag, Cement and Concrete Research, 36 (7) 1279-1285.

Li, J. and Yao, Y. (2001). "A study on creep and drying shrinkage of high performance concrete”, Cement and Concrete Research, 31 (8),1203-1206. 
Lothenbach, B., Le Saout, G., Ben Haha, M., Figi, R. and Wieland, E. (2012). "Hydration of a low-alkali CEM III/B-SiO 2 cement (LAC)”, Cement and Concrete Research. 42, 410-423.

Luan, Y., Ishida, T, Nawa,T. and Sagawa, T. (2012).”Enhanced model and simulation of hydration process of blast furnace slag in blended cement”, Journal of Advanced Concrete Technology, 10, 1-13

Luke, K. and Glasser, F.P. (1987). "Selective dissolution of hydrated blast furnace slag cements”, Cement and Concrete Research, 17 (2) 273-282.

Lumley, J.S., Gollop, R.S., Moir, G.K., and Taylor, H.F.W. (1960). "Degrees of reaction of the slag in some blends with Portland cements”, Cement and Concrete Research, 26 (1) (1996) 139-151.

Maekawa, K., Ishida, T. and Kishi, T. (2008). “Multi-scale modeling of structural concrete.” London and New York: Taylor \& Francis.

Ohsawa, S., Asaga, K., Goto, S. and Daimon, M. (1985). "Quantitative determination of fly ash in the hydrated fly ash- $\mathrm{CaSO}_{4} \cdot 2 \mathrm{H}_{2} \mathrm{O}-\mathrm{Ca}(\mathrm{OH})_{2}$ system", Cement and Concrete Research, 15, 357-366.

Otabe, Y. and Kishi, T. (2005). "Hydration and strength development model for quality prediction and support on construction management”, Seisankenkyu, 57 (2), 37-44 (In Japanese).

Powers T. C. (1960). "Physical properties of cement paste", Proceedings of the 4th ISCC, 2, 577-613.

Regourd, M. (1987). "Microstructure of cement blends containing fly ash, silica fume, slag and fillers", Materials Research Society Symposium Proceedings, 85, 187-200.

Regourd, M., Mortureux, B., Gautier, E., Hornain, H. and Volant, J. (1980). "Characterisation and thermal activation of slag cements", Proceedings of the 7th International Congress on the Chemistry of Cement, Paris, France, II (III), 105-111,

Regourd, M., Mortureux, B., and Hornain, H. (1983). "Use of condensed silica fume as filler in blended cements”, ACI Special Publication, 79, 847-866.

Richardson, I.G. and Groves, G.W.(1992). "Microstructure and microanalysis of hardened cement pastes involving ground granulated blast-furnace slag”, Journal of Materials Science, 27, 6204-6212.

Sagawa, T, Ishida, T, Luan, Y. and Nawa, T, (2010). "Hydrate composition analysis and micro structure characteristics of portland cement-blast furnace slag system." Journal of JSCE E, 66(3), 311-324. (In Japanese).

Sagawa, T. and Nawa, T, (2006a). "Hydration of blast furnace slag cement and effect of water to cement ratioon hydration of blast furnace slag cement " Cement Science and Concrete Technology, 60, 82-87. (In Japanese).

Sagawa, T. and Nawa, T, (2006b). "Quantitative hydration analysis of blast furnace slag cement by Rietveld method." Cement Research and Technology, 17,1-11. (In Japanese).

Sakai, E., Imoto, H. and Daimon, M. (2004). "Hydration and strength development of blast furnace slag cement”, Proceedings of JCI, 26 (1), 135-140 (In Japanese).

Schiller, K.K. (1958). “Mechanical properties of non-metallic materials”, Butterworths, London, 35-50

Talling, B. and Brandstetr, J. (1989). "Present state and future of alkali-activated slag concretes, Fly Ash, Silica Fume, Slag and Natural Pozzolans in Concrete” 1519-1545.

Tan, K. (1998). "Strengthening effects of finely ground fly ash, granulated blast furnace slag, and their combination", Cement and Concrete Research, 28, 1819-1825

Tanaka, H., Totani, Y and Saito, Y, (1983). "Structure of hydrated glasy blast furnace slag contents." ACI Special Publication, 79,963-977.

Taylor, R F. W. (1997). "Cement Chemistry." 2nd ed. Thomas Telford Ltd.

Weerdt, K. D., Haha, M. B., Saout, G. L., Kjellsen, K. O., Justnes, H. And Lothenbach, B., (2011), "Hydration mechanisms of ternary Portland cements containing limestone powder and fly ash", Cement and Concrete Research, 41, 279-291. 